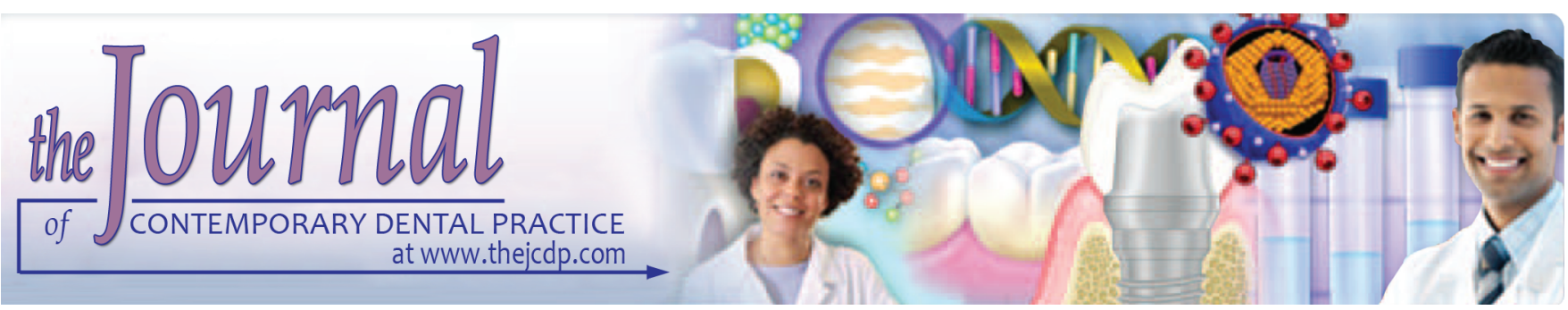

\title{
Assessment of Dental Arch Changes and Buccal Bone Thickness in Patients treated with Self-ligating Brackets
}

\author{
${ }^{1}$ Deolino J Ibiapina, ${ }^{2}$ Paula V Oltramari-Navarro, ${ }^{3}$ Ricardo L Navarro, ${ }^{4}$ Marcio R Almeida \\ ${ }^{5}$ Daniela L Mendonça, ${ }^{6}$ Ana CCF Conti
}

\begin{abstract}
Aims: To evaluate changes in transverse dimensions of upper arch and thickness of the buccal bone plate in patients undergoing orthodontic treatment during the leveling phase.

Materials and methods: Sixteen patients aged between 11 and 30 years, presenting with class I and II malocclusion, with minimum of $2 \mathrm{~mm}$ crowding treated without extraction, were divided into two groups: $\mathrm{Gl}(\mathrm{n}=8)$, self-ligating brackets (Easyclip Aditek), and GII $(n=8)$, conventional preadjusted brackets (3M Unitek). The intercanines, interpremolar, and intermolar widths were measured in dental casts using a digital caliper, before (T1) and after 6 months of treatment (T2). Measurements of the thickness of the bone plate were performed by using cone-beam computed tomography $(\mathrm{CBCT})$ scans and Dolphin three-dimensional program. Paired and nonpaired $t$ tests were applied to analyze the results in and between the groups for the changes in the transversal arch dimensions and buccal bone thickness.
\end{abstract}

Results: In all statistical tests, the significance level was set at $5 \%$. A nonsignificant increase in transverse dimensions and a slight reduction on thickness of the buccal bone plate were observed in both groups.

Conclusion: The dimensional changes of transverse and thickness of the bone plate during the initial phase of treatment were similar, regardless of the bracket design.

Clinical significance: It should be noted that the bracket design does not influence the treatment course regarding transversal dimensions and buccal bone thickness.

\footnotetext{
${ }^{1,2,4}$ Department of Orthodontics, University of North Paraná Londrina, Paraná, Brazil

${ }^{3}$ Department of Dentistry, State University of Maringá, Paraná Brazil

${ }^{5,6}$ Department of Orthodontics, Universidade do Sagrado Coração, Bauru, São Paulo, Brazil

Corresponding Author: Ana CCF Conti, Professor, Department of Orthodontics, Universidade do Sagrado Coração, Bauru, São Paulo, Brazil, Phone: +5514997957795, e-mail: accfconti@ uol.com.br
}

Keywords: Cone-beam computed tomography, Dental arch, Orthodontics.

How to cite this article: Ibiapina DJ, Oltramari-Navarro PV, Navarro RL, Almeida MR, Mendonça DL, Conti ACCF. Assessment of Dental Arch Changes and Buccal Bone Thickness in Patients treated with Self-ligating Brackets. J Contemp Dent Pract 2016;17(6):434-439.

Source of support: Nil

Conflict of interest: None

\section{INTRODUCTION}

In the past few years, orthodontics has faced techniques and application improvements so that large companies have gone on to offer self-ligating brackets, both in the active and in the passive form.

The main advantages of using self-ligating brackets include a reduction in friction, ${ }^{1}$ total and a secure ligation with the wire, ${ }^{2}$ anchorage loss avoidance, ${ }^{3}$ better infection control, ${ }^{3}$ lower discomfort for the patient, ${ }^{4}$ reduced time of treatment and increased intervals between appointments, ${ }^{5}$ and improved oral hygiene. ${ }^{6}$ Regarding the transversal arch changes, it is suggested that a passive expansion of the arches in the lateral rather than anterior direction occurs due to decreased friction and backward wire sliding. ${ }^{7}$ The result, thus, would be a greater production of alveolar bone, a greater amount of expansion, a reduced proclination of the anterior teeth, and a lower need for extractions. In contrast with these allegations, Pandis et $\mathrm{al}^{8}$ verified that self-ligating and conventional brackets alleviate crowding through similar mechanisms, which involve a buccal expansion of the lower incisors. Nevertheless, a slight posterior arch expansion is reported with self-ligating brackets. ${ }^{9,10}$

However, the effects upon the buccal or lingual bone have yet little scientific evidence, certainly resulting from the images superposition, making it difficult to visualize 
this area in two-dimensional (2D) radiographies. ${ }^{11}$ With cone-beam computed tomography (CBCT), it has become possible to study this anatomic region in quantitative and qualitative aspects thoroughly. ${ }^{12}$ The precision of CBCT measurements is related to image clearness and resolution, depending among other factors, on the voxel dimension (the smallest image unit). ${ }^{13}$ Thus, these images are adequate to evaluate the changes on the buccal bone thickness regarding transversal expansion. It is known, however, that in studies with animals and humans, dental movements in the buccal-lingual direction may cause bone dehiscences, ${ }^{14}$ an important factor to be considered and assessed with the use of CBCT images.

Considering the low level of evidence on this topic, the study of possible changes on both transversal dimensions and buccal bone thickness is deemed appropriate in patients after 6 months of orthodontic treatment with self-ligating and conventional brackets.

\section{MATERIALS AND METHODS}

For this prospective study, 16 patients (mean age 22.3 years, minimum 11, and maximum 30 years), 10 females and 6 males, were randomly divided into two groups. A coin was used so that "heads" was selected for the self-ligating group: GI ( $n=8$; subjects using passive self-ligating brackets, EasyClip, Aditek, Cravinhos, São Paulo, Brazil), and "tails" for the conventional group: GII ( $n=8$; subjects using conventional preadjusted brackets, 3M Unitek, Monrovia, CA, USA).

All patients presented Angle class I and II malocclusion and a minimum of $2 \mathrm{~mm}$ of anterior crowding. The presence of all permanent teeth, except 3rd molars, was considered the inclusion criteria.

Informed consent was signed by all parents or guardians of the patients after they received detailed information about the planned clinical trial and future

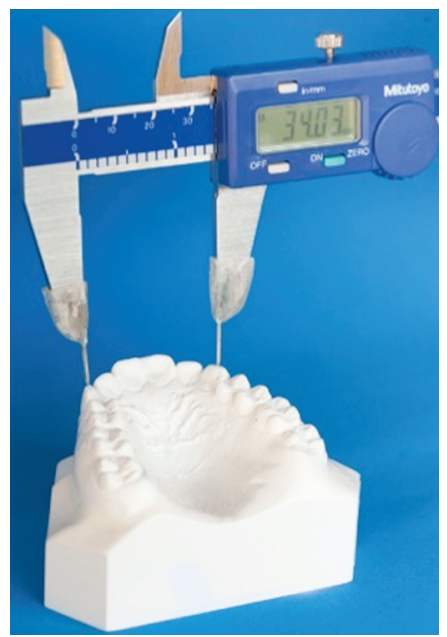

Fig. 1: Measurement of the intercanine width using a fine-pointed digital caliper orthodontic treatment of their children. This trial was approved by the ethical committee of the University of North Paraná (PT/0355/10).

Cone-beam computed tomography scans and dental casts were obtained from all patients in two time intervals, prior to the beginning of the orthodontic treatment (T1) and 6 months after it (T2).

A total of 136 transversal measurements of the upper dental arches were performed on the dental casts at T1 and T2 as follows: Intercanine width: Distance between the cusp tips of the canines; interfirst premolar width: Distance between the buccal cusp tips of the 1st premolars; intersecond premolar width: Distance between the buccal cusp tips of the 2nd premolars; and intermolar width: Distance between the mesiobuccal cusps of the 1st molars.

To avoid interoperator error, all measurements were made by a single investigator using a fine-pointed digital caliper (Mitutoyo Sul Americana LTDA, Suzano, SP, Brazil) (Fig. 1).

All CBCT scans were carried out using the same tomographer (i-Cat Imaging Sciences International, Hatfield, PA) with the protocol: $22 \times 16 \mathrm{~cm}$ FOV, 40 seconds, $120 \mathrm{kVp}, 36 \mathrm{~mA}$. This tomographer has high-resolution sensors and affords $0.4 \mathrm{~mm}$ voxel images.

In order to evaluate the buccal bone thickness, the CBCT scans were assessed by the same researcher by using the Dolphin 3D program (Version 11.5, Dolphin Imaging \& Management Solutions, Chatsworth, CA) with a level of sensitivity fixed at $25 \%$. These images were reconstructed, in the lateral right view of the patient, thereby generating an image similar to a lateral cephalometric $X$-ray, with the head repositioned in relation to the Frankfurt horizontal plane. After this procedure, the image was set upright so that it coincided with the long axis of each tooth evaluated, making it easier to visualize and assess the buccal bone thickness (Fig. 2).

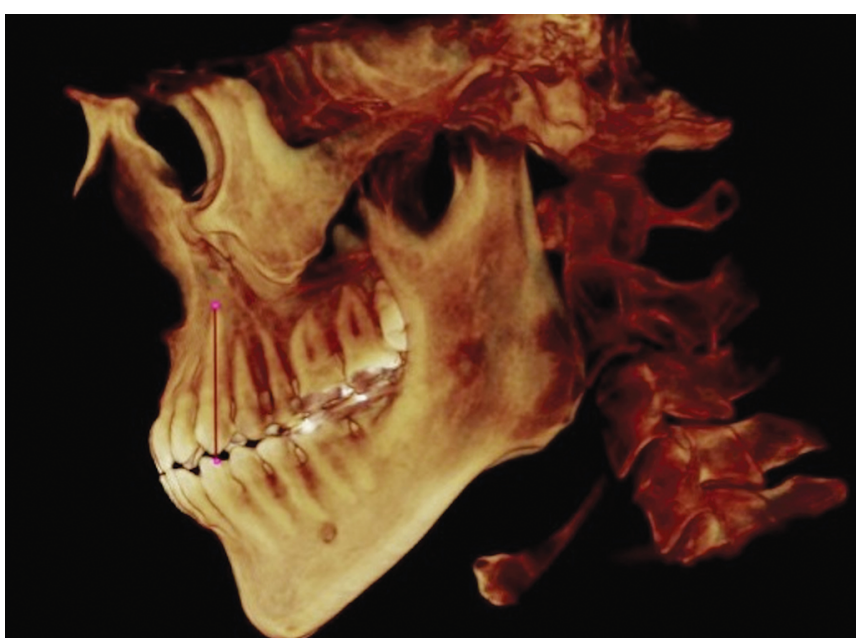

Fig. 2: Sagittal view set upright with the long axis of the tooth 


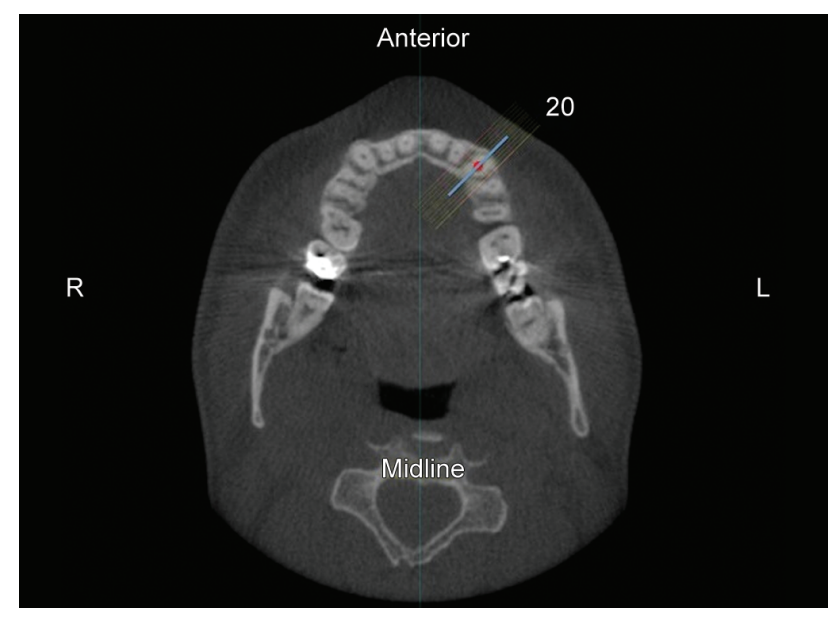

Fig. 3: Axial cut obtaining the center of the toothcrown in order to reconstruct the coronal cut

In the axial reconstruction of the maxilla, the most central point of the tooth crowns was marked in order to obtain an individualized coronal image of the canines, 1st and 2nd premolars, and 1st upper molars (Fig. 3). The images were then amplified in the coronal cut for better view at the cementoenamel junction and of the buccal bone. A 2nd and 3rd points were marked in the most buccal region of the tooth root, at a distance of 3 and $6 \mathrm{~mm}$ (respectively) from the cementoenamel junction, and a line was traced between the two points. The measurement of the buccal bone thickness was performed perpendicularly to that line (Fig. 4).

\section{STATISTICAL ANALYSIS}

All measurements were performed by single previously calibrated investigator in order to prevent interexaminer errors. Thirty days after the 1st evaluation, CBCT scans of 6 patients were randomly selected, and the respective measurements were repeated to determine intraexaminer errors by means of paired $t$ test (systematic errors) and Dahlberg formula (casual errors). ${ }^{15}$

The data were tested regarding the normal distribution by applying the Shapiro-Wilk test, and parametric tests

Table 1: Comparison of the transverse upper arch changes $(\mathrm{mm})$ between T1 and T2 for the patients in group I (self-ligating brackets)

\begin{tabular}{|c|c|c|c|c|c|c|}
\hline \multirow[b]{2}{*}{ Measurement } & \multicolumn{2}{|c|}{$T 1$} & \multicolumn{2}{|c|}{$T 2$} & \multicolumn{2}{|l|}{$T 2-T 1$} \\
\hline & $M$ & $S D$ & $M$ & $S D$ & $M \pm S D$ & $p$-value \\
\hline $\begin{array}{l}\text { Intercanine } \\
\text { width }\end{array}$ & 35.49 & 1.37 & 35.85 & 1.74 & $\begin{array}{l}0.36 \pm \\
2.02\end{array}$ & $0.63 \mathrm{NS}$ \\
\hline $\begin{array}{l}\text { Interfirst } \\
\text { premolar width }\end{array}$ & 41.57 & 2.57 & 43.35 & 2.34 & $\begin{array}{l}1.77 \pm \\
2.15\end{array}$ & $0.05 \mathrm{NS}$ \\
\hline $\begin{array}{l}\text { Intersecond } \\
\text { premolar width }\end{array}$ & 46.47 & 2.75 & 48.35 & 2.52 & $\begin{array}{l}1.88 \pm \\
1.86\end{array}$ & $0.02^{*}$ \\
\hline $\begin{array}{l}\text { Interfirst molar } \\
\text { width }\end{array}$ & 52.66 & 3.10 & 52.70 & 3.78 & $\begin{array}{l}0.04 \pm \\
1.30\end{array}$ & $0.93 \mathrm{NS}$ \\
\hline
\end{tabular}

*Statistically significant; n.s.: Statistically no significant difference; Mean (M), standard deviation (SD), difference between T1 and T2 (T2-T1), and p-value

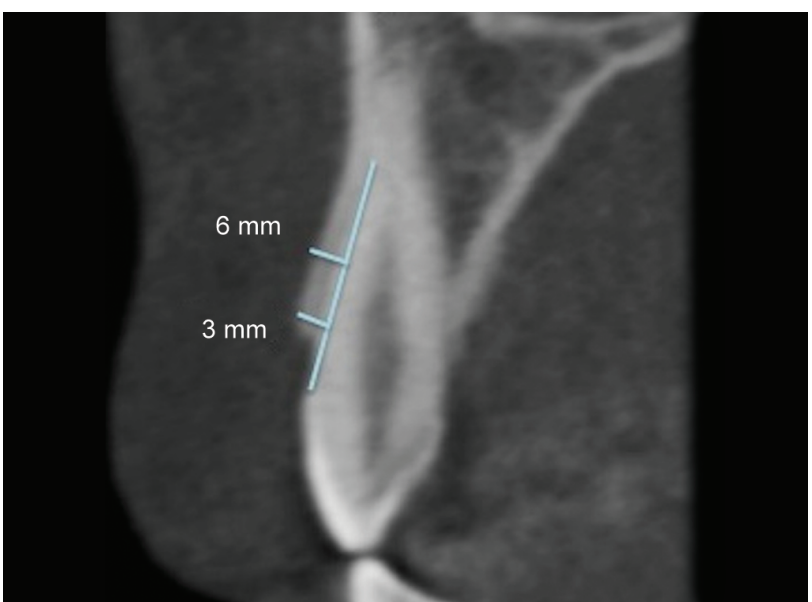

Fig. 4: Coronal cut showing the measurement of the buccal bone thickness at $3 \mathrm{~mm}$ apical from cementoenamel junction

could be used. The results were described by parameters like mean and standard deviation of T1 and T2 measurements for both groups. A paired $t$ test was used to evaluate the transversal dimensions changes and the variations in buccal bone thickness for each group between $\mathrm{T} 1$ and $\mathrm{T} 2$ periods, and a nonpaired t test was used for comparison between groups.

The statistical analysis was made using the software GraphPad Prism 5.0 (GraphPad Software Inc., La Jolla, CA, USA) and BioEstat 5.0 (Mamirauá Institute, Belém, PA, Brazil). In all statistical tests, the significance level was set at $5 \%$.

\section{RESULTS}

Regarding the systematic and casual errors, the results indicated that no statistically significant differences occurred between the two measurements.

Concerning the transversal arch changes T2-T1, GI showed no statistically significant increase, with exception for the intersecond premolar width $(1.88 \mathrm{~mm})$, as shown in Table 1.

For GII, the results indicated an increase in all transversal dimensions. However, all these changes were not statistically significant (Table 2). Furthermore,

Table 2: Comparison of the transverse upper arch changes ( $\mathrm{mm}$ ) between T1 and T2 for the patients in group II (conventional preadjusted brackets)

\begin{tabular}{|c|c|c|c|c|c|c|}
\hline \multirow[b]{2}{*}{ Measurement } & \multicolumn{2}{|c|}{$T 1$} & \multicolumn{2}{|c|}{$T 2$} & \multirow{2}{*}{$\frac{T 2-T 1}{M \pm S D}$} & \multirow[b]{2}{*}{ p-value } \\
\hline & $M$ & $S D$ & $M$ & $S D$ & & \\
\hline $\begin{array}{l}\text { Intercanine } \\
\text { width }\end{array}$ & 32.43 & 2.90 & 33.25 & 2.24 & $\begin{array}{l}0.82 \pm \\
2.08\end{array}$ & $0.30 \mathrm{NS}$ \\
\hline $\begin{array}{l}\text { Interfirst } \\
\text { premolar width }\end{array}$ & 39.99 & 2.75 & 41.56 & 3.17 & $\begin{array}{l}1.57 \pm \\
2.55\end{array}$ & $0.12 \mathrm{NS}$ \\
\hline $\begin{array}{l}\text { Intersecond } \\
\text { premolar width }\end{array}$ & 44.99 & 2.91 & 46.07 & 3.61 & $\begin{array}{l}1.08 \pm \\
2.62\end{array}$ & $0.28 \mathrm{NS}$ \\
\hline $\begin{array}{l}\text { Interfirst molar } \\
\text { width }\end{array}$ & 49.42 & 3.80 & 50.18 & 3.36 & $\begin{array}{l}0.76 \pm \\
2.35\end{array}$ & $0.39 \mathrm{NS}$ \\
\hline
\end{tabular}

NS: Statistically no significant difference; Mean (M), standard deviation (SD), difference between T1 and T2 (T2-T1), and p-value 
Table 3: Comparison of the difference in the transverse arch changes between GI (self-ligating brackets) and GII (conventional preadjusted brackets)

\begin{tabular}{llllllll}
\hline & \multicolumn{2}{c}{ GI } & & \multicolumn{2}{c}{ GII } & \\
\cline { 2 - 3 } Measurement & $M$ & $S D$ & & & $S D$ & p-value \\
\hline Intercanine width & 0.36 & 2.02 & & 0.82 & 2.08 & $0.66 \mathrm{NS}$ \\
Interfirst premolar width & 1.77 & 2.15 & & 1.57 & 2.55 & $0.86 \mathrm{NS}$ \\
Intersecond premolar width & 1.88 & 1.86 & & 1.08 & 2.62 & $0.49 \mathrm{NS}$ \\
Interfirst molar width & 0.04 & 1.30 & & 0.76 & 2.35 & $0.46 \mathrm{NS}$ \\
\hline
\end{tabular}

NS: Statistically no significant difference; Mean (M), standard deviation (SD), and p-value

no statistically significant differences were observed between the groups regarding transversal dimensions changes (Table 3).

Considering the differences (T2-T1) in the buccal bone thickness at $3 \mathrm{~mm}$ from the cementoenamel junction between the groups, it was observed that a small decrease of the buccal bone occurred similarly in both groups, which was regarded as statistically nonsignificant (Table 4).

When taking into account the differences (T2-T1) in the buccal bone thickness at $6 \mathrm{~mm}$ from the cementoenamel junction between groups, a decreasing tendency remained for group I. Nevertheless, for group II, this decreasing tendency was only observed for the canine $(-0.048 \mathrm{~mm})$ (Table 5).

\section{DISCUSSION}

The efficiency of new materials is the key to justify its worldwide use. This concept could also be applied to selfligating brackets, which so far lacks scientific evidence. ${ }^{10}$

One of the difficulties of randomized clinical trials concerns the achievement of paired samples, and their size following inclusion criteria. Regardless of the size of this sample, this fact could not jeopardize the results, once these are similar to those shown in the literature. ${ }^{16-18}$

Concerning the transversal measurements, the results of our study showed that all measures increased, in groups I and II respectively, as follows: The intercanine width 0.82 and $0.36 \mathrm{~mm}$; the interfirst premolar width 1.57 and $1.77 \mathrm{~mm}$; the intersecond premolar width 1.08 and $1.88 \mathrm{~mm}$; the interfirst molar width 0.76 and $0.04 \mathrm{~mm}$,

Table 4: Comparison of the difference in the buccal bone thickness at $3 \mathrm{~mm}$ apical from cementoenamel junction between GI (selfligating brackets) and GII (conventional preadjusted brackets)

\begin{tabular}{lllllll}
\hline \multirow{2}{*}{$\begin{array}{l}\text { Buccal bone } \\
\text { thickness changes }\end{array}$} & \multicolumn{2}{c}{ GI } & & \multicolumn{2}{c}{ GIl } & \\
\cline { 2 - 3 } \cline { 5 - 6 } & $M$ & $S D$ & & $M$ & $S D$ & $p$-value \\
\hline $13 / 23$ & -0.067 & 0.08 & & -0.069 & 0.15 & $0.97 \mathrm{NS}$ \\
$14 / 24$ & -0.033 & 0.23 & & -0.16 & 0.28 & $0.15 \mathrm{NS}$ \\
$15 / 25$ & -0.06 & 0.40 & & -0.20 & 0.36 & $0.29 \mathrm{NS}$ \\
$16 / 26$ & -0.11 & 0.25 & & -0.02 & 0.24 & $0.31 \mathrm{NS}$ \\
\hline
\end{tabular}

NS: Statistically no significant difference; Mean (M), standard deviation (SD), and p-value as seen in Tables 1 and 2. These slight increases in transversal dimensions were statistically insignificant, possibly due to the mild crowding shown by the patients and due to the reduced treatment time. Notwithstanding, these results showed that self-ligating brackets, similarly to conventional ones, promote a mild expansion of the upper arch, once the differences between the groups were not statistically significant (Table 3).

In both groups, expansion was most pronounced in the premolar region. These results corroborate with the study of Cattaneo et $\mathrm{al}^{18}{ }^{18}$ in which transversal changes in the upper arch were assessed, with greater transversal increase in the interfirst premolars width (4.3 and $4.5 \mathrm{~mm}$ ); and intersecond premolars width $(4.0$ and $3.3 \mathrm{~mm}$ ) for the groups that used passive and active self-ligating brackets respectively. Their results showed a greater magnitude, probably explained by the whole treatment period evaluated. Other studies also indicated that the greater transversal increase was registered in the intercanine and interpremolar width, and the smaller increase occurred in the intermolar width. ${ }^{9,10}$ When considering the differences between groups, no statistically significant differences were observed regarding the transversal changes, similar to the literature findings. ${ }^{16,19,20}$

Also corroborating to our results, the transversal dimensions of the upper arch were assessed by Tecco et $\mathrm{al}^{17}$ comparing two models of brackets, self-ligating (Damon-3MX, Ormco) and conventional (Victory series MBT, 3M Unitek). The sample of their study comprised 40 patients with mild upper crowding, similar to our study. The intercanine, interfirst premolar, intersecond premolar, and intermolar width were recorded at the beginning of the treatment (T0) and 12 months thereafter (T1). They verified a significant increase in all the transversal measurements from $\mathrm{T} 0$ to $\mathrm{T} 1$, but did not observe a significant difference between the self-ligating and conventional groups. It is important to highlight that the treatment time in our study ( 6 months) was half of the time of their study (12 months); in addition, the archwire alloy and shape may have influenced the small magnitude of the expansion that we found.

Table 5: Comparison of the difference in the buccal bone thickness at $6 \mathrm{~mm}$ apical from cementoenamel junction between GI (selfligating brackets) and GII (conventional preadjusted brackets)

\begin{tabular}{lrllllll}
\hline \multirow{2}{*}{$\begin{array}{l}\text { Buccal bone } \\
\text { thickness changes }\end{array}$} & \multicolumn{2}{c}{$G I$} & & \multicolumn{2}{c}{ Gll } & \\
\cline { 2 - 3 } \cline { 5 - 6 } & $M$ & $S D$ & & $M$ & $S D$ & p-value \\
\hline $13 / 23$ & -0.048 & 0.09 & & -0.069 & 0.10 & $0.55 \mathrm{NS}$ \\
$14 / 24$ & 0.027 & 0.20 & & -0.10 & 0.19 & $0.07 \mathrm{NS}$ \\
$15 / 25$ & 0.004 & 0.29 & & -0.33 & 0.63 & $0.06 \mathrm{NS}$ \\
$16 / 26$ & 0.017 & 0.26 & & -0.09 & 0.52 & $0.44 \mathrm{NS}$ \\
\hline
\end{tabular}

NS: Statistically no significant difference; Mean (M), standard deviation (SD), and p-value 
The present study also evaluated the thickness of the buccal bone plate with $\mathrm{CBCT}$ scans, at the height of 3 and $6 \mathrm{~mm}$ from the cementoenamel junction, in the canines, premolars, and 1st molars (Tables 4 and 5). The results indicated a slight decrease in the buccal bone thickness in both groups, except for GI in the premolar and molar region at the height of $6 \mathrm{~mm}$. Based on the mild transversal arch changes found, this small effect upon the bone could be expected. These bone thickness variations were similar in both groups, regardless of the type of bracket used. Cattaneo et $\mathrm{al}^{18}$ observed a greater transversal changes in the 2nd premolars width, and thus a decrease of the buccal bone thickness.

Regarding physiologic expansion and buccal bone apposition, claimed as advantages of the self-ligating brackets, especially the passive ones, ${ }^{21}$ it was not confirmed in our study, neither in Cattaneo et al. ${ }^{18}$ Current evidence has shown that many of the advantages attributed to these brackets remain unproved. ${ }^{22}$

Comparatively, our results showed a slight increase in the transversal arch dimensions and a decrease in the buccal bone thickness, both regarded as statistically and clinically insignificant. These changes were similar regardless of the type of bracket, self-ligating or conventional. These findings corroborate to those of the literature. ${ }^{10,11,18,23-25}$ However, further long-term clinical studies are necessary to confirm the results observed in this research.

\section{CONCLUSION}

Based on the similarity of the changes in the transversal arch dimensions and in the buccal bone thickness between the groups, the orthodontic treatment performed during the first 6 months achieved the same results, regardless of the bracket design (passive self-ligating or conventional preadjusted).

\section{CLINICAL SIGNIFICANCE}

When the orthodontists are choosing the bracket type for a patient, they should not consider the effects either in the transversal distances or in the buccal bone thickness because the bracket design does not influence these conditions in the leveling and aligning phase.

\section{REFERENCES}

1. Kim TK, Kim KD, Baek SH. Comparison of frictional forces during the initial leveling stage in various combinations of self-ligating brackets and arch wires with a custom-design typodont system. Am J Orthod Dentofacial Orthop 2008 Feb;133(2):187.e15-187.e24.

2. Harradine NWT. Self-ligating brackets: where are we now? J Orthod 2003 Sep;30(3):262-273.
3. Berger JL. The influence of the speed brackets self-ligating design on force levels in tooth movement: a comparative in vitro study. Am J Orthod Dentofacial Orthop 1990 Mar;97(3): 219-228.

4. Maijer R, Smith DC. Time savings with self-ligating brackets. J Clin Orthod 1990 Jan;24(1):29-31.

5. Eberting JJ, Straja SR, Tuncay OC. Treatment time, outcome, and patient satisfaction comparisons of Damon and conventional brackets. Clin Orthod Res 2001 Nov;4(4):228-234.

6. Paduano S, Cioffi I, Iodice G, Rapuano A, Silva R. Time efficiency of self-ligating vs conventional brackets in orthodontics: effect of appliances and ligating systems. Prog Orthod 2008;9(2):74-80.

7. Damon D. The rationale, evolution and clinical application of the self-ligating bracket. Clin Orthod Res 1998 Aug;1(1):52-61.

8. Pandis N, Polychronopoulou A, Makou M, Eliades T. Mandibular dental arch changes associated with treatment of crowding using self-ligating and conventional brackets. Eur J Orthod 2010 Jun;32(3):248-253.

9. Scott P, DiBiase AT, Sherrif M, Cobourne MT. Alignment efficiency of Damon 3 self-ligating and conventional orthodontic bracket systems: a randomized clinical trial. Am J Orthod Dentofacial Orthop 2008 Oct;134(4):470.e1-470.e8.

10. Fleming PS, DiBiase AT, Sarri G, Lee RT. Comparison of mandibular arch changes during alignment and leveling with 2 preadjusted edgewise appliances. Am J Orthod Dentofacial Orthop 2009 Sep;136(3):340-347.

11. Martins PP, Garib DG, Greghi SLA, Henriques JFC. Avaliação periodontal dos incisivos inferiores em pacientes tratados ortodonticamente com extrações de quatro pré-molares. Rev Fac Odontol Bauru 2002;10(4):245-251.

12. Garib DG, Raymundo R Jr, Raymundo MV, Raymundo DV, Ferreira SN. Tomografia computadorizada de feixe cônico (Cone beam): entendendo esse novo método de diagnóstico por imagem com promissora aplicabilidade na Ortodontia. Rev Dental Press Ortod Ortop Facial 2007 Mar/Apr;12(2):139-156.

13. Ludlow JB, Laster WS, See M, Bailey LJ, Hershey HG. Accuracy of measurements of mandibular anatomy in cone beam computed tomography images. Oral Surg Oral Med Oral Pathol Oral Radiol Endod 2007 Apr;103(4):534-542.

14. Wennström JL, Lindhe J, Sinclair F, Thilander B. Some periodontal tissue reactions to orthodontic tooth movement in monkeys. J Clin Periodontal 1987 Mar;14(3):121-129.

15. Houston WJB. The analysis of errors in orthodontic measurements. Am J Orthod 1983 May;83(5):383-390.

16. Brito DM, Conti ACCF, Almeida MR, Oltramari-Navarro PVP, Navarro RL, Almeida RR. Avaliação das Alterações Dimensionais dos arcos dentários inferiores produzidas por braquetes autoligáveis e convencionais. Rev Clín Ortodontia Dental Press 2011;10:92-99.

17. Tecco S, Tete S, Perillo L, Chimenti C, Festa F. Maxillary arch width changes during orthodontic treatment with fixed selfligating and traditional straight-wire appliances. World J Orthod 2009 Winter;10(4):290-294.

18. Cattaneo PM, Treccani M, Carlsson K, Thorgeirsson T, Myrda A, Cevidanes LHS, Melsen B. Transversal maxillary dentoalveolar changes in patients treated with active and passive self-ligating brackets: a randomized clinical trial using CBCT - scans and digital models. Orthod Craniofac Res 2011 Nov;14(4):222-233.

19. Bollen AM, Cunha-Cruz J, Bakko DW, Huang GJ, Hujoel PP. The effects of orthodontic therapy on periodontal health: 
a systematic review of controlled evidence. J Am Dent Assoc 2008 Apr;139(4):413-422.

20. Lagravère MO, Carey J, Heo G, Toogood GHR, Major PW. Transverse, vertical, and anteroposterior changes from bone-anchored maxillary expansion vs traditional maxillary rapid expansion: a randomized clinical trial. Am J Orthod Dentofacial Orthop 2010 Mar;137(3):304.e1-304.e12.

21. Damon DH. The Damon low-friction bracket: a biologically compatible straight-wire system. J Clin Orthod 1998 Nov;32(11): 670-680.

22. Chen SSH, Geoffrey MG, Kim GJE, Smith KC, Huang G. Systematic review of self-ligating brackets. Am J Orthod Dentofacial Orthop 2010 Jun;137(6):726.e1-726.e18.
23. Pliska BT, Beyer JP, Larson BE. A comparison of resistance to sliding of self-ligating brackets under an increasing applied moment. Angle Orthod 2011 Sep;81(5):794-799.

24. Fleming PS, Lee RT, Marinho V, Johal A. Comparison of maxillary arch dimensional changes with passive and active self-ligation and conventional brackets in the permanent dentition: a multicenter, randomized controlled trial. Am J Orthod Dentofacial Orthop 2013 Aug;144(2):185-193.

25. Almeida MR, Futagami R, Conti ACCF, Oltramari-navarro PVP, Navarro LR. Dentoalveolar mandibular changes selfligating versus conventional bracket systems: a CBCT and dental cast study. Dental Press J Orthod 2015 May-Jun;20(3): 50-57. 